\title{
MMP11 and CD2 as novel prognostic factors in hormone receptor-negative, HER2-positive breast cancer
}

\author{
Jinil Han ${ }^{1}$ Yoon-La Choi ${ }^{2,3,4} \cdot$ Haein $\mathrm{Kim}^{5} \cdot$ Jun Young Choi ${ }^{5} \cdot$ \\ Se Kyung Lee ${ }^{6} \cdot$ Jeong Eon Lee ${ }^{4,6} \cdot$ Joon-Seok Choi ${ }^{7}$. \\ Sarah Park ${ }^{8} \cdot$ Jong-Sun Choi ${ }^{8}$ Y Young Deug Kim? \\ Seok Jin Nam ${ }^{6}$ Byung-Ho Nam ${ }^{10,11} \cdot$ Mi Jeong Kwon ${ }^{12,13}$. \\ Young Kee Shin ${ }^{5,8,14}$
}

Received: 14 November 2016/Accepted: 6 April 2017/Published online: 13 April 2017

(c) The Author(s) 2017. This article is an open access publication

\begin{abstract}
Purpose More accurate prediction of patient outcome based on molecular subtype is required to identify patients who will benefit from specific treatments.

Methods We selected novel 16 candidate prognostic genes, including 10 proliferation-related genes (p-genes) and 6 immune response-related genes (i-genes), from the gene list identified in our previous study. We then analyzed the association between their expression, measured by quantitative real-time reverse transcription-PCR in formalin-
\end{abstract}

Jinil Han and Yoon-La Choi have contributed equally to this work.

Electronic supplementary material The online version of this article (doi:10.1007/s10549-017-4234-4) contains supplementary material, which is available to authorized users.

\footnotetext{
Mi Jeong Kwon

mjkwon94@knu.ac.kr

Young Kee Shin

ykeeshin@snu.ac.kr

Jinil Han

jinil@gencurix.com

Yoon-La Choi

ylachoi@skku.edu

Haein Kim

khi8710@snu.ac.kr

Jun Young Choi

comfly@snu.ac.kr

Se Kyung Lee

sekyung.lee@samsung.com

Jeong Eon Lee

paojlus@hanmail.net

Joon-Seok Choi

joonschoi@naver.com
}

fixed, paraffin-embedded tissues, and clinical outcome in 819 breast cancer patients according to molecular subtype. Results The prognostic significance of clinical and gene variables varied according to the molecular subtype. Univariate analysis showed that positive lymph node status was significantly correlated with the increased risk of distant metastasis in all subtypes except the hormone receptornegative, HER2-positive (HR-/HER2+) subtype. Most p-genes were significantly associated with poor prognosis in patients with the HR+/HER2 - subtype, whereas i-genes correlated with a favorable outcome in patients with HR-/HER2 + breast cancer. In HR-/HER2+ breast cancer, four genes (three i-genes BTN3A2, CD2, and TRBC1 and the p-gene MMP11) were significantly associated with distant metastasis-free survival (DMFS). A new prognostic

Sarah Park

sarah-@hanmail.net

Jong-Sun Choi

jsc1@snu.ac.kr

Young Deug Kim

todnos@abionbio.com

Seok Jin Nam

seokjin.nam@samsung.com

Byung-Ho Nam

byunghonam@heringsglobal.com

Gencurix, Inc., Seoul 08394, Korea

2 Laboratory of Cancer Genomics and Molecular Pathology, Samsung Medical Center, Sungkyunkwan University School of Medicine, Seoul 06356, Korea

3 Department of Pathology and Translational Genomics, Samsung Medical Center, Sungkyunkwan University School of Medicine, Seoul 06356, Korea 
model for HR-/HER2+ breast cancer based on the expression of MMP11 and CD2 was developed and the DMFS for patients in the high-risk group according to our model was significantly lower than that for those in the low-risk group. Multivariate analyses revealed that our risk score is an independent prognostic factor for DMFS. Moreover, C-index showed that our risk score has a superior prognostic performance to traditional clinicopathological factors.

Conclusions Our new prognostic model for HR-/HER2+ breast cancer provides more accurate information on the risk of distant metastasis than traditional clinical prognostic factors and may be used to identify patients with a good prognosis in this aggressive subtype of breast cancer.

Keywords Breast cancer - Hormone receptor-negative . HER2-positive (HR-/HER2+) breast cancer · Prognostic model - Risk of distant metastasis - Immune responserelated genes (i-genes) · Proliferation-related genes (p-genes)

$\begin{array}{ll}\text { Abbreviations } \\ \text { C-index } & \text { Harrell's concordance index } \\ \text { CI } & \text { Confidence interval } \\ \text { DFS } & \text { Disease-free survival } \\ \text { DMFS } & \text { Distant metastasis-free survival } \\ \text { ER } & \text { Estrogen receptor } \\ \text { FFPE } & \text { Formalin-fixed, paraffin-embedded } \\ \text { HER2 } & \text { Human epidermal growth factor receptor 2 } \\ \text { HR } & \text { Hormone receptor } \\ \text { IRB } & \text { Institutional review board } \\ \text { NPI } & \text { Nottingham prognostic index } \\ \text { OS } & \text { Overall survival } \\ \text { PR } & \text { Progesterone receptor } \\ \text { qRT-PCR } & \text { Quantitative real-time reverse transcription- } \\ & \text { PCR } \\ \text { TNBC } & \text { Triple-negative breast cancer }\end{array}$

4 Department of Health Sciences and Technology, SAIHST, Sungkyunkwan University, Seoul 06356, Korea

5 Laboratory of Molecular Pathology and Cancer Genomics, Department of Pharmacy, College of Pharmacy, Seoul National University, 1 Gwanak-ro, Gwanak-gu, Seoul 08826, Korea

6 Department of Surgery, Samsung Medical Center, Sungkyunkwan University School of Medicine, Seoul 06356, Korea

7 College of Pharmacy, Catholic University of Daegu, Gyeongbuk 38430, Korea

8 The Center for Anti-cancer Companion Diagnostics, BioMAX/N-Bio, Seoul National University, Seoul 08826, Korea

$9 \quad$ R\&D center, ABION Inc., Seoul 08394, Korea

\section{Introduction}

Breast cancer is a highly heterogeneous disease and is currently classified into four general molecular subtypes according to the status of hormone receptors, including estrogen receptor (ER) or progesterone receptor (PR), and human epidermal growth factor receptor 2 (HER2) [1]. Each subtype has distinct molecular characteristics and although individual patient prognosis varies, patients with the hormone receptor-positive, HER2-negative (HR+/HER2-) subtype generally have a more favorable prognosis whereas those with hormone receptor-negative (HR-) breast cancer have a poor prognosis [2-4]. Because treatment strategies for breast cancer are dependent on molecular subtype and patient prognosis, it is important to identify specific prognostic biomarkers for each molecular subtype to determine appropriate treatments.

Gene expression-based approaches provide significant prognostic or predictive information, and commercial assays such as Oncotype DX [5, 6], MammaPrint [7, 8], Prosigna [9, 10], and EndoPredict [11] based on multigene expression profiling in frozen or formalin-fixed, paraffin-embedded (FFPE) samples have been developed for ER-positive (ER+) breast cancer. These assays predict the risk of distant recurrence after hormone therapy and are useful to identify patients who will benefit from adjuvant chemotherapy by discriminating high- and low-risk patients with early ER+ breast cancer. However, there are certain limitations to the currently available assays that use multigene expression signatures based on proliferation-related genes (p-genes) including diminished prognostic ability to predict the late distant recurrence (beyond 5 years from diagnosis or primary treatment). Furthermore, commercialized kits based on various multigene predictors of clinical outcome are prognostic only for HR+ subtypes, whereas there is no available commercial assay for $\mathrm{HR}$ - breast cancer. Meta-analysis using publicly available microarray data from over 2100 patients showed that the key biological processes associated with the clinical outcome of patients with

10 Department of Cancer Control and Policy, Graduate School of Cancer Science and Policy, National Cancer Center, Goyang, Gyeonggi-do 10408, Korea

11 Present Address: HERINGS, The Institute of Advanced Clinical and Biomedical Research, Seoul 06051, Korea

12 College of Pharmacy, Kyungpook National University, 80 Daehak-ro, Buk-gu, Daegu 41566, Korea

13 Research Institute of Pharmaceutical Sciences, College of Pharmacy, Kyungpook National University, Daegu 41566, Korea

14 Department of Molecular Medicine and Biopharmaceutical Sciences, Graduate School of Convergence Science and Technology, Seoul National University, Seoul 08826, Korea 
breast cancer differs according to the molecular subtype [12]. This study selected seven prototype genes (AURKA, PLAU, $S T A T 1, V E G F, C A S P 3, E S R 1$, and ERBB2) representing different biological processes, proliferation, tumor invasion/ metastasis, immune response, angiogenesis, apoptosis phenotypes, and ER and HER2 signaling, respectively, and assessed the association between the expression of these seven gene modules and clinical variables and relapse-free survival of patients in each subtype of the breast cancer. The results showed that the prognostic performance of the proliferation module was limited to the ER+/HER2- subgroup, and genes associated with tumor invasion and immune response have prognostic value in ER-/HER2 - or ER-/HER2+ subtypes. Recent studies reporting prognostic genes or gene signatures predicting recurrence or distant metastasis for HR - breast cancer [13-16] further confirm that expression of immune response-related genes (i-genes) is primarily associated with good clinical outcome in patients with HR- breast cancer, unlike the strong prognostic significance of p-genes, which predict recurrence in $\mathrm{HR}+$ breast cancer. However, these results are based mainly on gene expression microarray data, and validation of most of the identified prognostic genes or signatures has not been performed.

We previously identified 384 candidate prognostic genes associated with distant metastasis in patients with lymph node-negative ( $\mathrm{LN}-$ ) early breast cancer using public microarray gene expression data [17]. This study aimed to identify novel prognostic genes associated with the risk of distant metastasis in patients with various subtypes of breast cancer from the candidate list established in our previous study. We validated the expression of 16 candidate prognostic genes by performing quantitative real-time reverse transcription-PCR (qRT-PCR) in a large number of FFPE tissue samples, and we then assessed the association between their expression and the risk of distant metastasis in 819 patients with breast cancer. Based on the resulting set of significant prognostic genes, we developed a prognostic model to predict the risk of distant metastasis in HR-/HER2+ breast cancer.

\section{Materials and methods}

\section{Ethical statement}

This study was approved by the Institutional Review Board (IRB) of the Samsung Medical Center (SMC) (Seoul, Korea) and performed in accordance with the Declaration of Helsinki. The study was retrospective and informed consents from the patients involved in the study were not required, as per the guidelines of the IRB. Patient information was anonymized and de-identified prior to analysis.

\section{Study population}

Our study adhered to the Reporting Recommendations for Tumor Marker Prognostic Studies (REMARK) criteria in the design, analysis, and interpretation of the results [18]. A total of 997 FFPE tissue specimens were obtained from patients with breast cancer who underwent curative resection for primary tumors with $\mathrm{LN}$ dissection at the SMC between 1994 and 2002. We also obtained 50 frozen tissue samples paired with FFPE samples from the same patients. Detailed inclusion/exclusion criteria for tissue samples are described in Supplementary materials and methods. Molecular subtypes of breast cancer were categorized as $\mathrm{HR}+1$ HER $2-($ ER + or PR +/HER $2-), \mathrm{HR}+/ \mathrm{HER} 2+(\mathrm{ER}+$ or $\mathrm{PR}+/ \mathrm{HER} 2+), \mathrm{HR}-/ \mathrm{HER} 2+$ (ER-/PR-/HER $2+$ ), or triple-negative breast cancer (TNBC, ER-/PR-/HER2-) according to the expression status of ER, PR, and HER2, as classified in our previous study [19].

\section{Selection of candidate prognostic genes}

From 384 candidate genes identified in our previous study using public gene expression microarray data [17], a total of 30 candidate genes were selected based on the following criteria: (1) high correlation with either proliferation or immune response, (2) high variability between samples (large interquartile range), and (3) high mean expression value. Based on the results of qRT-PCR, 16 genes with high correlation of expression between FFPE and frozen tissues were further selected. For details, see Supplementary materials and methods.

\section{qRT-PCR and normalization of qRT-PCR data}

RNA extraction and qRT-PCR were performed as described in Supplementary materials and methods. The relative expression value of each gene was calculated based on the difference between the average $\mathrm{Cq}$ value of the three reference genes (CTBP1,CUL1, and UBQLN1) and the target $\mathrm{Cq}$ value for each sample:

$$
\begin{aligned}
\Delta C_{\mathrm{q}_{-}} \operatorname{target}= & \left(\left(C_{\mathrm{q}_{-}} C T B P 1+C_{\mathrm{q}_{-}} C U L 1+C_{\mathrm{q}_{-}} U B Q L N 1\right) / 3\right) \\
& -C_{\mathrm{q}_{-}-} \operatorname{target}+30
\end{aligned}
$$

\section{Development of the prognostic model for $\mathrm{HR}-/$ HER2 + breast cancer and cross validation}

Based on stepwise multivariate analyses results, a prognostic model to predict the risk of distant metastasis in HR-/HER2+ breast cancer was developed. Relative expression values of the two prognostic genes normalized 
by the average expression level of three reference genes were used to calculate the risk score, a molecular predictor of distant metastasis. The risk score was defined as follows:

Risk score $=0.45 \times \Delta C_{\mathrm{q} \_} M M P 11-0.48 \times \Delta C_{\mathrm{q} \_} C D 2$

Higher values indicate a higher risk of distant metastasis. For development and performance evaluation of the prognostic model, a 10-fold cross validation procedure was used [20].

We compared the prognostic performance of our prognostic model with other prognostic models based on clinical variables, including The Nottingham prognostic index (NPI) score [21] and two web-based prediction tools, SNAP (www.CancerMath.net) [22] and PREDICT (www. predict.nhs.uk) [23, 24]. The Harrell's concordance index (C-index) [25] was calculated to estimate the discrimination capability of each prognostic model and to compare their prognostic performance. Detailed information on the development of the prognostic model is provided in the Supplementary materials and methods.

\section{Statistical analyses}

Distant metastasis-free survival (DMFS) was defined as the time from the date of surgery for the primary tumor to the date of distant metastasis. Overall survival (OS) and Disease-free survival (DFS) were defined as described in our previous study [26]. Univariate and multivariate analyses were performed using Cox proportional hazard model. For univariate and multivariate analyses, missing $C_{\mathrm{q}}$ values were imputed using the algorithm developed by McCall et al. [27]. In particular, selected variables in univariate analysis were entered in a stepwise multivariate Cox proportional hazard model to determine independent contributions of predictors for the primary endpoint. Probability of distant metastasis was estimated by the Kaplan-Meier method and the log-rank test was used to test the differences in survival between the groups. Differences were to be considered statistically significant if the $P$ value was less than 0.05 . All statistical analyses were performed using $R$ 3.2.0 (http://r-project.org).

\section{Results}

\section{Patient characteristics}

Of the 997 FFPE tissue samples, histologically ineligible samples or those with an insufficient amount of tissue were excluded, as were samples that produced an insufficient amount of RNA. Gene expression was measured in a total of 926 FFPE samples by qRT-PCR. Cases with missing $C \mathrm{q}$ values for reference genes in the qRT-PCR data or with missing clinical information were further excluded, resulting in a total of 819 breast cancer patients with informative clinical data that were finally included in the analysis. The median patient age was 47.3 years (range 23.8-81.2), and the mean tumor size was $2.8 \pm 1.6 \mathrm{~cm}$ (mean $\pm \mathrm{SD}$ ). Of the 819 patients, $51.6 \%$ (423/819) were $\mathrm{LN}-$, whereas $48.4 \%(396 / 819)$ were $\mathrm{LN}+$. A total of $86.3 \%(707 / 819)$ of the patients received adjuvant chemotherapy. The details on the clinicopathological characteristics of breast cancer patients grouped by molecular subtypes are illustrated in Table 1. Of the 819 cases, the majority comprised $\mathrm{HR}+$ tumors, including HR +/HER2 - $(50.1 \%, 410 / 819)$ and HR+/HER2+ $(13.7 \%, 112 / 819)$ subtypes. The HR+/HER2 - subtype had the highest percent of histologic grade 1 and 2 tumors, whereas the HR-/HER2+ and TNBC subtypes consisted of a higher proportion of grade 3 tumors.

Kaplan-Meier curves for DMFS, DFS, and OS were generated according to molecular subtype. The median follow-up durations for DMFS, DFS, and OS were 9.68 (range 0.04-19.46), 9.45 (range 0.04-19.46), and 10.33 years (range 0.05-19.46), respectively. During this entire follow-up period, there were no significant differences in patient survival between molecular subtypes (Supplementary Fig. S1A). However, in terms of 5-year OS and DFS, significant $(P<0.001$ for OS $)$ or marginally significant $(P=0.069$ for DFS $)$ differences in patient survival between molecular subtypes were observed (Supplementary Fig. S1B). Patients with HR-/HER2+ subtype showed poorer 5-year survival than those with the HR+/HER2 - subtype (Supplementary Fig. S1B).

\section{Univariate analysis of clinical variables according to molecular subtype}

First, we analyzed the association of traditional clinicopathological factors with clinical outcome according to molecular subtype. Univariate analysis for DMFS showed that clinical variables such as larger tumor size, positive $\mathrm{LN}(\mathrm{LN}+)$ involvement, and higher histologic grade were significantly associated with an increased risk of distant metastasis in the HR+/HER2- subtype (Table 2). However, only LN status was significantly correlated with DMFS in HR +/HER $2+$ cancers, whereas tumor size and LN status were significant for DMFS in TNBC. The significance of tumor size was limited to HER2- subtypes, including HR+/HER2- and TNBC. Of note, none of the clinical variables were significant in HR-/HER2+ breast cancer. 
Table 1 Clinical characteristics of the breast cancer patients in this study

\begin{tabular}{|c|c|c|c|c|c|}
\hline & $\begin{array}{l}\text { Total } \\
(n=819) \\
\text { No. }(\%)\end{array}$ & $\begin{array}{l}\text { HR+/HER2- } \\
(n=410) \\
\text { No. }(\%)\end{array}$ & $\begin{array}{l}\text { HR }+/ \text { HER } 2+ \\
(n=112) \\
\text { No. }(\%)\end{array}$ & $\begin{array}{l}\text { HR-/HER } 2+ \\
(n=105) \\
\text { No. }(\%)\end{array}$ & $\begin{array}{l}\text { TNBC } \\
(n=192) \\
\text { No. }(\%)\end{array}$ \\
\hline Median age (min-max) (years) & $47.3(23.8-81.2)$ & $47.3(25.2-80.5)$ & $45.5(26.0-77.4)$ & $52.8(24.3-77.8)$ & $46.0(23.8-81.2)$ \\
\hline \multicolumn{6}{|l|}{ Age (years) } \\
\hline$<50$ & $486(59.3)$ & $241(58.8)$ & $76(67.9)$ & $43(41.0)$ & $126(65.6)$ \\
\hline$\geq 50$ & $333(40.7)$ & $169(41.2)$ & $36(32.1)$ & $62(59.0)$ & $66(34.4)$ \\
\hline \multicolumn{6}{|l|}{ Tumor size $(\mathrm{cm})$} \\
\hline$\leq 2$ & $325(39.7)$ & $183(44.6)$ & $39(34.8)$ & $32(30.5)$ & $71(37.0)$ \\
\hline $2-5$ & $438(53.5)$ & $204(49.8)$ & $65(58.0)$ & $63(60.0)$ & $106(55.2)$ \\
\hline$>5$ & $56(6.8)$ & $23(5.6)$ & $8(7.1)$ & $10(9.5)$ & $15(7.8)$ \\
\hline \multicolumn{6}{|l|}{ Lymph node status } \\
\hline Negative & $423(51.6)$ & $203(49.5)$ & $45(40.2)$ & $59(56.2)$ & $116(60.4)$ \\
\hline Positive & $396(48.4)$ & $207(50.5)$ & $67(59.8)$ & $46(43.8)$ & $76(39.6)$ \\
\hline \multicolumn{6}{|l|}{$\mathrm{pN}$} \\
\hline 0 & $423(51.7)$ & $203(49.5)$ & $45(40.2)$ & $59(56.2)$ & $116(60.4)$ \\
\hline 1 & $214(26.1)$ & $112(27.3)$ & $40(35.7)$ & $22(21.0)$ & $40(20.8)$ \\
\hline 2 & $97(11.8)$ & $51(12.4)$ & $16(14.3)$ & $11(10.5)$ & $19(9.9)$ \\
\hline 3 & $85(10.4)$ & $44(10.7)$ & $11(9.8)$ & $13(12.4)$ & $17(8.9)$ \\
\hline \multicolumn{6}{|l|}{ Pathologic stage } \\
\hline I & 204 (24.9) & 113 (27.6) & $17(15.2)$ & $20(19.0)$ & $54(28.1)$ \\
\hline II & 417 (50.9) & $197(48.0)$ & $64(57.1)$ & $58(55.2)$ & $98(51.0)$ \\
\hline III & $198(24.2)$ & $100(24.4)$ & $31(27.7)$ & $27(25.7)$ & $40(20.8)$ \\
\hline \multicolumn{6}{|l|}{ Histologic grade } \\
\hline 1 & $93(11.4)$ & $77(18.8)$ & $8(7.1)$ & $4(3.8)$ & $4(2.1)$ \\
\hline 2 & $300(36.6)$ & $199(48.5)$ & $37(33.0)$ & $24(22.9)$ & $40(20.8)$ \\
\hline 3 & $366(44.7)$ & $123(30)$ & $59(52.7)$ & $66(62.9)$ & $118(61.5)$ \\
\hline Unknown & $60(7.3)$ & $11(2.7)$ & $8(7.1)$ & $11(10.5)$ & $30(15.6)$ \\
\hline \multicolumn{6}{|l|}{ Nuclear grade } \\
\hline 1 & $81(9.9)$ & $60(14.6)$ & $7(6.3)$ & $2(1.9)$ & $12(6.3)$ \\
\hline 2 & $402(49.1)$ & $256(62.4)$ & $55(49.1)$ & $35(33.3)$ & $56(29.2)$ \\
\hline 3 & 307 (37.5) & $81(19.8)$ & $46(41.1)$ & $65(61.9)$ & 115 (59.9) \\
\hline Unknown & $29(3.5)$ & $13(3.2)$ & $4(3.6)$ & $3(2.9)$ & $9(4.7)$ \\
\hline \multicolumn{6}{|l|}{ Hormone therapy } \\
\hline No & $301(36.8)$ & $21(5.1)$ & $11(9.8)$ & $96(91.4)$ & $173(90.1)$ \\
\hline Yes & $508(62.0)$ & 379 (92.4) & $101(90.2)$ & $9(8.6)$ & $19(9.9)$ \\
\hline Unknown & $10(1.2)$ & $10(2.4)$ & $0(0.0)$ & $0(0.0)$ & $0(0.0)$ \\
\hline \multicolumn{6}{|l|}{ Chemotherapy } \\
\hline No & $110(13.4)$ & $68(16.6)$ & $14(12.5)$ & $14(13.3)$ & $14(7.3)$ \\
\hline Yes & 707 (86.3) & $342(83.4)$ & 97 (86.6) & $90(85.7)$ & 178 (92.7) \\
\hline Unknown & $2(0.3)$ & $0(0.0)$ & $1(0.9)$ & $1(1.0)$ & $0(0.0)$ \\
\hline \multicolumn{6}{|l|}{ Radiotherapy } \\
\hline No & $352(43.0)$ & $162(39.5)$ & $50(44.6)$ & $59(56.2)$ & $81(42.2)$ \\
\hline Yes & $465(56.8)$ & $247(60.2)$ & $61(54.5)$ & $46(43.8)$ & $111(57.8)$ \\
\hline Unknown & $2(0.2)$ & $1(0.2)$ & $1(0.9)$ & $0(0.0)$ & $0(0.0)$ \\
\hline \multicolumn{6}{|l|}{ NPI } \\
\hline 1 & 149 (18.2) & 113 (27.6) & $14(12.5)$ & $7(6.7)$ & $15(7.8)$ \\
\hline 2 & $210(25.6)$ & 113 (27.6) & $23(20.5)$ & $28(26.7)$ & $46(24.0)$ \\
\hline
\end{tabular}


Table 1 continued

\begin{tabular}{llllll}
\hline & $\begin{array}{l}\text { Total } \\
(n=819) \\
\text { No. }(\%)\end{array}$ & $\begin{array}{l}\text { HR+/HER2 } \\
\left(\begin{array}{l}n=410) \\
\text { No. }(\%)\end{array}\right.\end{array}$ & $\begin{array}{l}\text { HR+/HER2 } \\
(n=112) \\
\text { No. }(\%)\end{array}$ & $\begin{array}{l}\text { HR-/HER2+ } \\
(n=105) \\
\text { No. }(\%)\end{array}$ & $\begin{array}{l}\text { TNBC } \\
(n=192) \\
\text { No. }(\%)\end{array}$ \\
\hline 3 & $286(34.9)$ & $113(27.6)$ & $51(45.5)$ & $44(41.9)$ & $78(40.6)$ \\
4 & $113(13.8)$ & $58(14.1)$ & $17(15.2)$ & $75(14.3)$ & $23(12.0)$ \\
Unknown & $61(7.5)$ & $13(3.2)$ & $7(6.3)$ & $11(10.5)$ & $30(15.6)$ \\
\hline
\end{tabular}

$H R$ hormone receptor, $H E R 2$ human epidermal growth factor receptor 2, TNBC triple-negative breast cancer, $p N$ pathologic nodal status, $N P I$ Nottingham prognostic index

Univariate analysis results for DFS and OS were similar to those for DMFS (Supplementary Table S1). None of the clinical variables were significantly associated with DFS or OS in HR-/HER2+ subtype tumors. In HR+/HER2+ tumors, younger age $($ age $<50)$ and $\mathrm{LN}+$ status showed a significant association with increased risk of recurrence, whereas none of the clinical variables were significant for OS.

\section{Univariate analysis of gene variables according to molecular subtype}

Univariate analysis for gene variables showed that the association between expression of each of the 16-candidate prognostic genes and distant metastasis differed according to molecular subtype. Most p-genes showed a significant association with DMFS in the HR+/HER2- subtype. High level expression of nine p-genes correlated significantly with a greater risk of distant metastasis in this subtype (Table 3).

Subgroup analysis by LN status in each molecular subtype showed a slight difference in the significant genes between $\mathrm{LN}+$ and $\mathrm{LN}-$ cancers. In particular, in $\mathrm{HR}+/$ HER2-, LN- tumors, five p-genes (FOXM1, MK167, $R R M 2, T O P 2 A$, and $U B E 2 C$ ) were statistically significant and the expression of immune response-related $B T N 3 A 2$ showed a marginal significance in DMFS (Table 3). However, BTN3A2 was not significant in $\mathrm{LN}+$ breast cancer. Three p-genes (MMP11, RRM2, and UBE2C) were significant in DMFS in the HR+/HER2+ subtype. In HR-/HER2+ breast cancer, MMP11 and three i-genes (BTN3A2, CD2, and TRBC1) were significantly associated with clinical outcomes, whereas no clinical variable was significant. Higher MMP11 expression was significantly associated with higher risk of distant metastasis, while higher expression levels of $B T N 3 A 2, C D 2$, and TRBC1 were related to favorable outcomes (Table 3 ). The significant association of these i-genes with a favorable outcome was only observed in $\mathrm{LN}-$ breast cancer, and not in $\mathrm{LN}+$ tumors.

Consistent with the findings for DMFS, genes significantly associated with DFS or OS were dependent on molecular subtype and the list of genes was similar to that associated with DMFS (Supplementary Tables S2, S3). A significant relationship between high level expression of i-genes and favorable outcome was also observed only in HR-/HER2+ breast cancer. Subgroup analysis by LN status in each molecular subtype showed only a slight difference between $\mathrm{LN}-$ and $\mathrm{LN}+$ breast cancer in the list of genes significantly associated with DFS or OS.

\section{Multivariate analysis according to molecular subtype}

Using the clinical and gene variables that were significant in the univariate analysis, stepwise variable selection of multivariate analysis was performed to identify independent predictors of DMFS for each molecular subtype. Hazard ratios and 95\% confidence intervals (CIs) for DMFS are shown in Table 4. In HR-/HER2+ breast cancer, MMP11 (hazard ratio 1.49; 95\% CI 1.08-2.04; $P=0.014$ ) and $C D 2$ (hazard ratio 0.66 ; 95\% CI 0.47-0.94; $P=0.022)$ retained their statistical significance for DMFS in multivariate analysis. These results demonstrated that the expression of MMP11 and $C D 2$ are independent prognostic factors for HR-/HER2+ breast cancer. In other subtypes, positive LN status was an independent negative prognostic factor. Moreover, TOP $2 A$ was independently associated with DMFS in the HR+/HER2- subtype.

With regard to DFS, the expression of MMP11 and $U B E 2 C$ were independent prognostic factors in $\mathrm{HR}-1$ HER2+ breast cancer (Supplementary Table S4). Unexpectedly, increased $U B E 2 C$ expression showed a significant association with the decreased risk of recurrence in this subtype. In HR+/HER2- cancers, $\mathrm{LN}+$ status and expression of $M M P 11$ and TOP $2 A$ were independently associated with the increased risk of recurrence. Age, LN status, and $U B E 2 C$ expression were independent prognostic factors in the HR+/HER2+ cancer. LN status was an independent negative prognostic factor only in TNBC.

Independent prognostic factors for OS in HR-/HER2+ breast cancer included the expression of MMP11 and BTN3A2 (Supplementary Table S4). In the HR+/HER2+ subtype, RRM2 expression retained its significance. By 


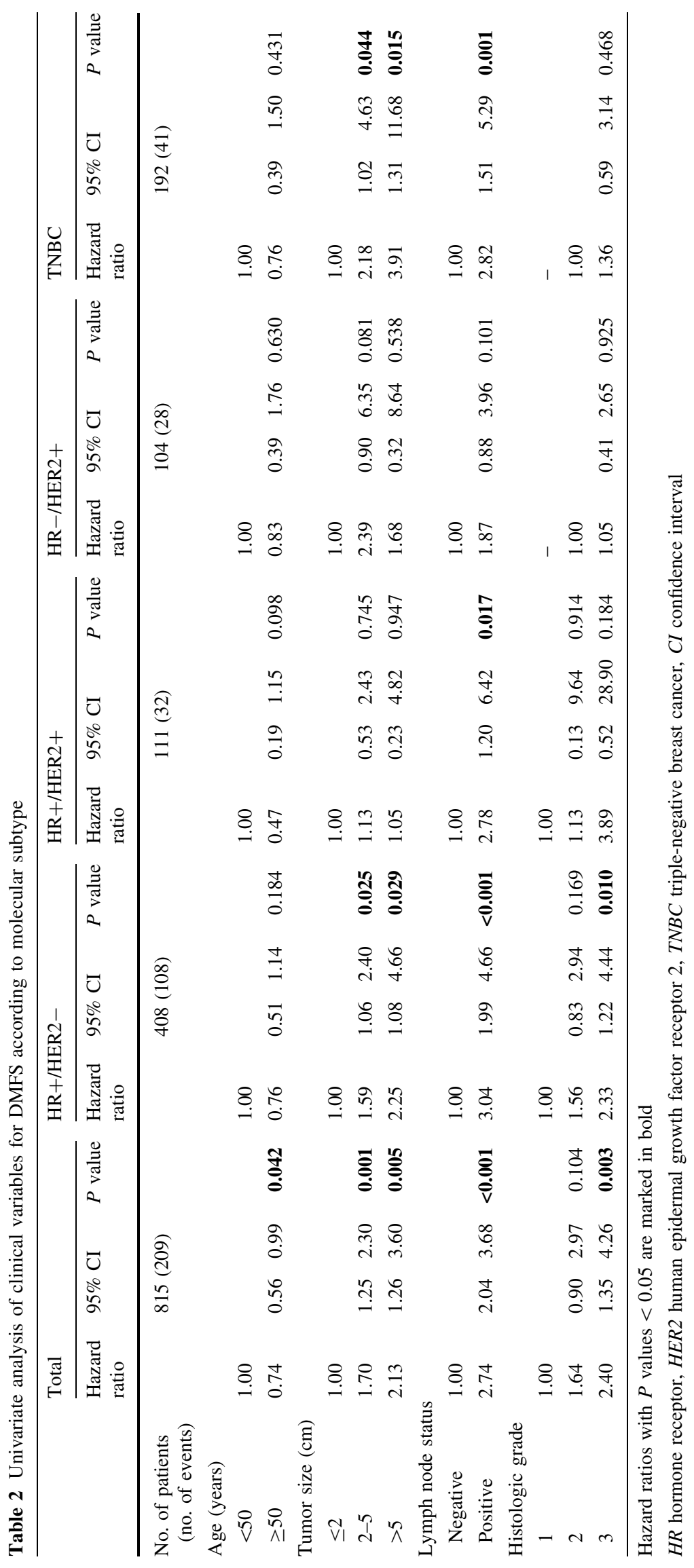




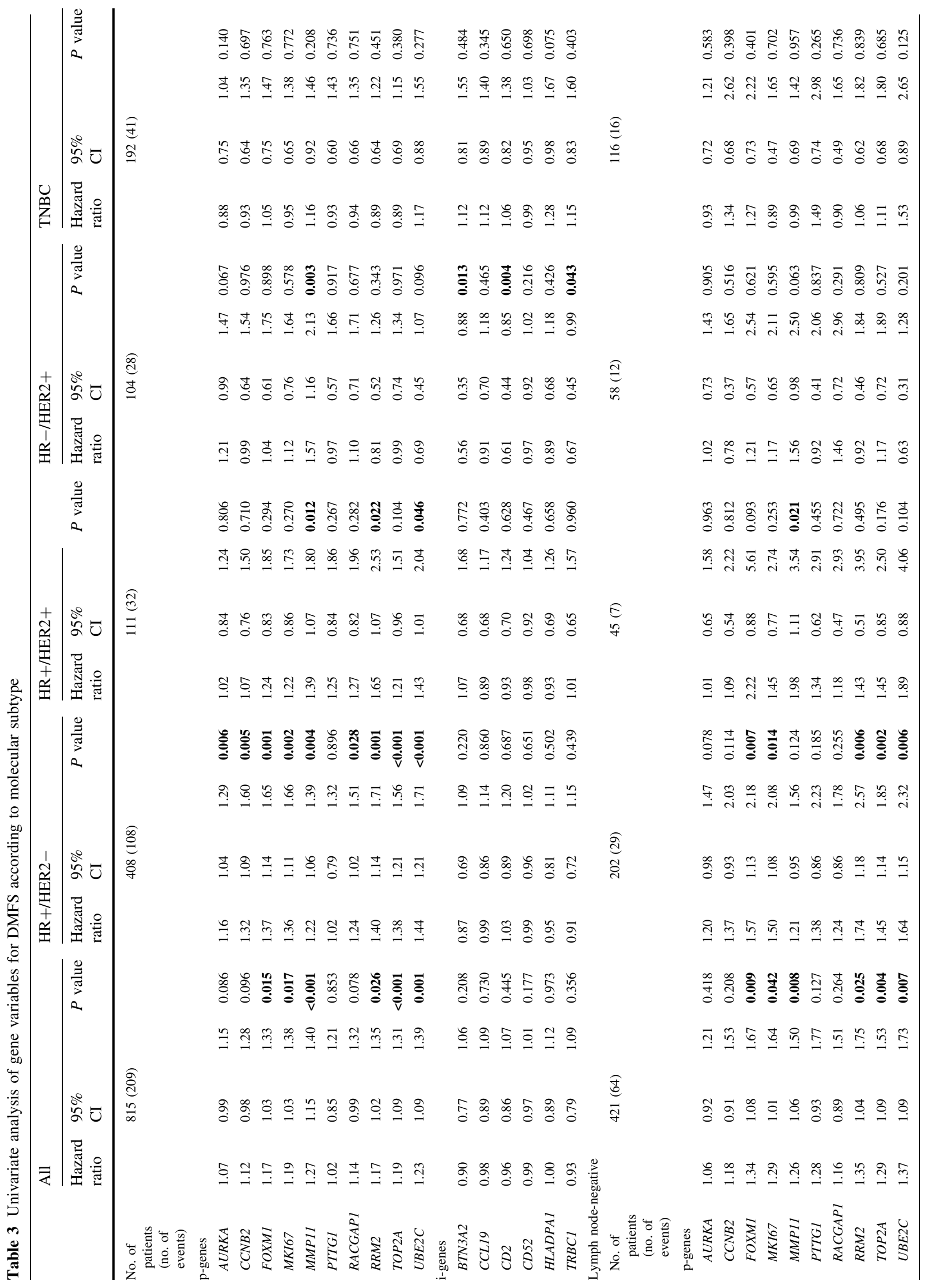




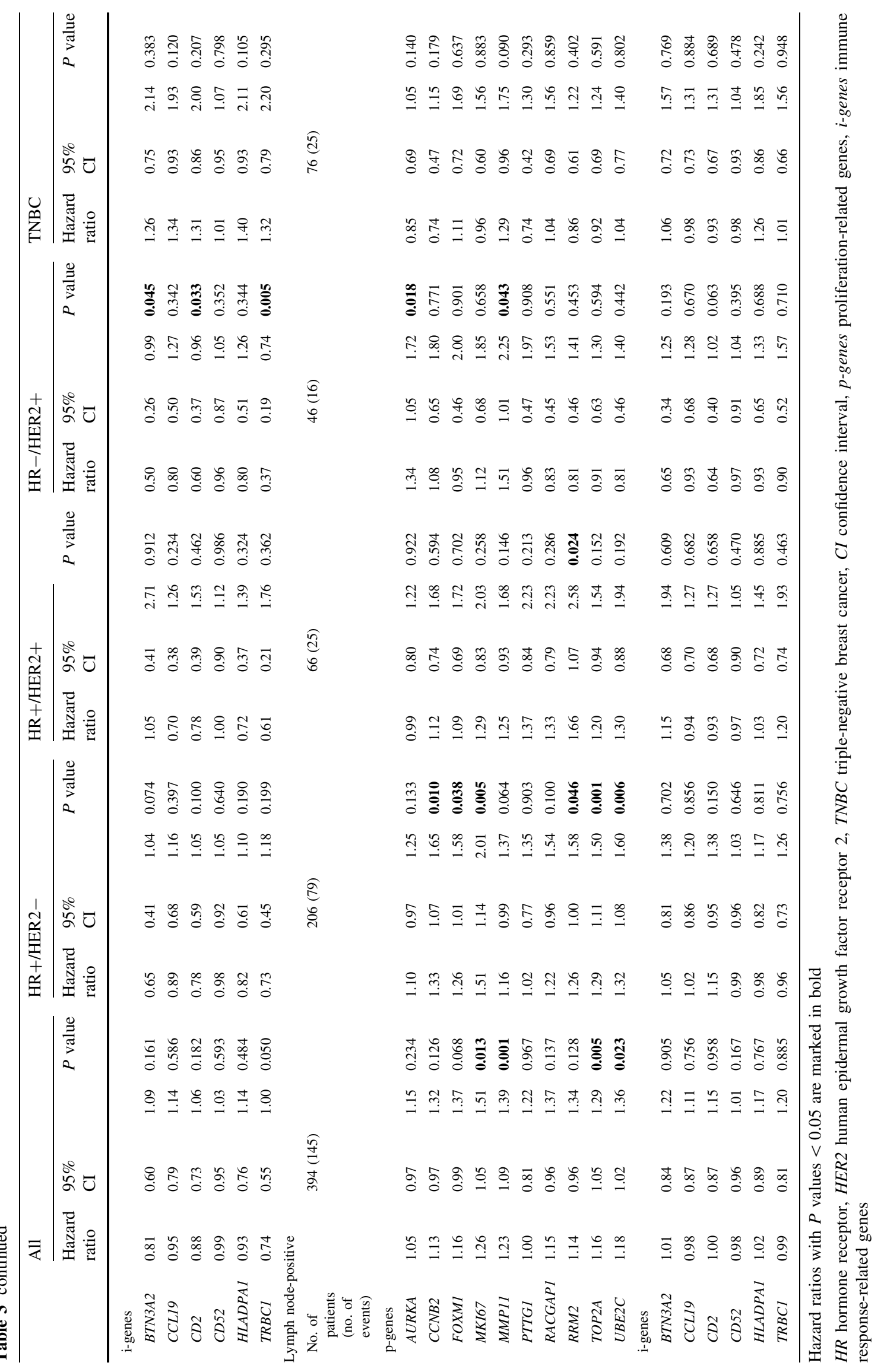




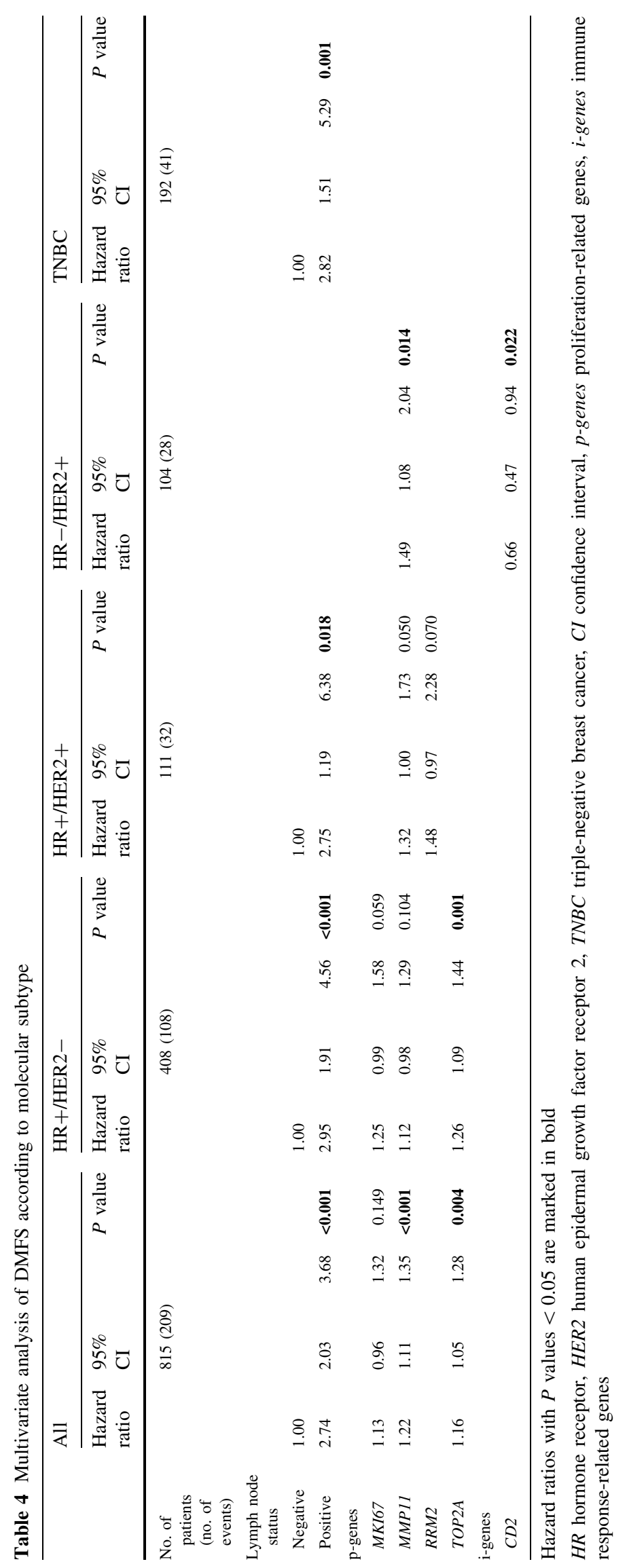


contrast, LN status only was an independent prognostic for OS in HER2- breast cancer, whereas no gene variable was significant.

\section{Prognostic performance of the risk model for distant metastasis in HR-/HER2+ breast cancer}

To assess the prognostic significance of our prognostic model, HR-/HER2 + breast cancer patients were classified into two groups, high risk and low risk, according to the risk score developed by our prognostic model. KaplanMeier curves demonstrated that DMFS for patients in the

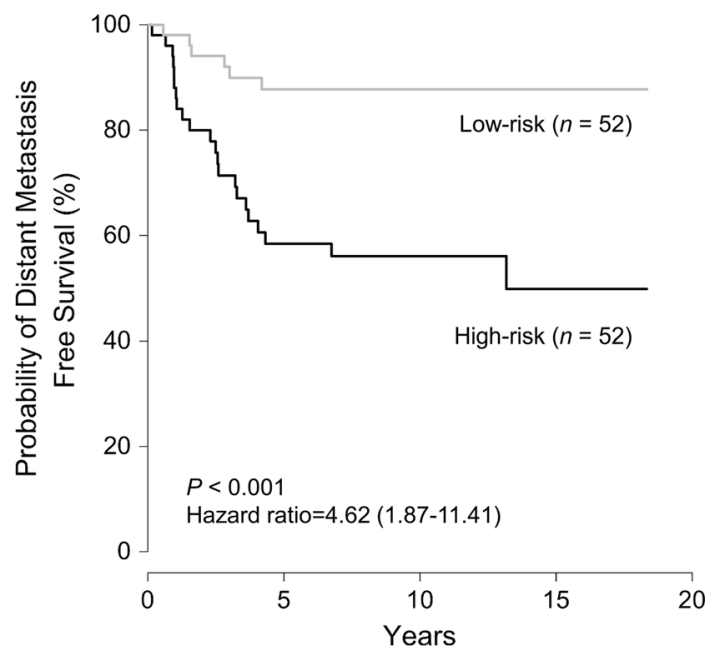

Fig. 1 Kaplan-Meier plot of distant metastasis-free survival (DMFS) in low-risk and high-risk groups defined by our prognostic model in patients with HR-/HER2 + breast cancer. Survival estimates between two risk groups were compared using the log-rank test and the hazard ratio was derived using Cox proportional hazard model high-risk group was significantly lower than for those in the low-risk group (log-rank test; $P<0.001$; Fig. 1). The probabilities of DMFS at 10 years for patients in the highrisk and low-risk groups were $56.1 \%$ and $87.7 \%$, respectively. That is, patients in the high-risk group had a significantly higher 10 -year distant metastasis rate $(43.9 \%)$ than those in the low-risk group (12.3\%). When we analyzed the difference in clinical characteristics between the risk groups, we found no significant differences between the two groups (Supplementary Table S5). These results indicate that our prognostic model is useful for differentiating HR-/HER2+ breast cancer patients at high risk and low risk of distant metastasis, whereas clinical variables alone are not sufficient to identify these patients. There was no association between clinical variables with our risk score in HR-/HER2+ breast cancer (Supplementary Fig. S2).

In the multivariate analysis after adjustments for traditional clinicopathological parameters, our risk score retained statistical significance (hazard ratio $2.49 ; 95 \% \mathrm{CI}$ 1.46-4.24; $P=0.001$; Table 5) and was more significant than other prognostic models based on clinical variables (Table 6). These results indicate that our model is an independent prognostic indicator of risk of distant metastasis in HR-/HER2+ breast cancer.

Our model showed the best performance in predicting the risk of distant metastasis with the highest C-index (0.694) among other traditional prognostic factors (Fig. 2) or prognostic models based on clinicopathological factors alone (Supplementary Fig. S3). These results reinforce that our prognostic model is superior to other conventional models based on clinical variables alone in predicting the risk of distant metastasis in HR-/HER2+ breast cancer

Table 5 Multivariate analysis of our prognostic model and traditional clinicopathological parameters for DMFS in HR-/HER2+ breast cancer

\begin{tabular}{|c|c|c|c|c|c|c|}
\hline & \multicolumn{3}{|c|}{ Univariate analysis } & \multicolumn{3}{|c|}{ Multivariate analysis } \\
\hline & Hazard ratio & $95 \% \mathrm{CI}$ & $P$ value & Hazard ratio & $95 \% \mathrm{CI}$ & $P$ value \\
\hline No. of patients (no. of events) & & $104(28)$ & & & $104(28)$ & \\
\hline Risk score & 2.36 & $(1.48-3.78)$ & $<0.001$ & 2.49 & $(1.46-4.24)$ & 0.001 \\
\hline \multicolumn{7}{|l|}{ Histologic grade } \\
\hline 1 and 2 & 1.00 & & & 1.00 & & \\
\hline 3 & 1.27 & $(0.50-3.21)$ & 0.618 & 1.79 & $(0.69-4.65)$ & 0.229 \\
\hline \multicolumn{7}{|l|}{ Lymph node status } \\
\hline Negative & 1.00 & & & 1.00 & & \\
\hline Positive & 1.87 & $(0.88-3.96)$ & 0.101 & 1.67 & $(0.71-3.91)$ & 0.238 \\
\hline Tumor size $(\mathrm{cm})$ & & & 0.211 & & & 0.155 \\
\hline$\leq 2$ & 1.00 & & & 1.00 & & \\
\hline $2-5$ & 2.39 & $(0.90-6.35)$ & 0.081 & 2.85 & $(0.94-8.61)$ & 0.063 \\
\hline$>5$ & 1.68 & $(0.32-8.64)$ & 0.538 & 1.44 & $(0.25-8.35)$ & 0.684 \\
\hline
\end{tabular}

Hazard ratios with $P$ values $<0.05$ are marked in bold

$C I$ confidence interval 
Table 6 Multivariate analysis of our prognostic model and other prognostic models based on traditional clinicopathological parameters for DMFS in HR-/HER2+ breast cancer

\begin{tabular}{|c|c|c|c|c|c|c|}
\hline & \multicolumn{3}{|c|}{ Univariate analysis } & \multicolumn{3}{|c|}{ Multivariate analysis } \\
\hline & Hazard ratio & $95 \% \mathrm{CI}$ & $P$ value & Hazard ratio & $95 \% \mathrm{CI}$ & $P$ value \\
\hline No. of patients (No. of events) & & $104(28)$ & & & $104(28)$ & \\
\hline Risk score & 2.36 & $(1.48-3.78)$ & $<0.001$ & 2.49 & $(1.46-4.24)$ & 0.001 \\
\hline PREDICT & 1.03 & $(1.02-1.05)$ & $<0.001$ & 1.02 & $(1.00-1.05)$ & 0.082 \\
\hline SNAP & 1.04 & $(1.02-1.07)$ & 0.001 & 1.06 & $(1.01-1.11)$ & 0.021 \\
\hline NPI score & 1.56 & $(1.15-2.14)$ & 0.005 & 2.06 & $(1.07-3.97)$ & 0.031 \\
\hline
\end{tabular}

Hazard ratios with $P$ values $<0.05$ are marked in bold

CI confidence interval, PREDICT www.predict.nhs.uk, SNAP www.CancerMath.net, NPI Nottingham prognostic index

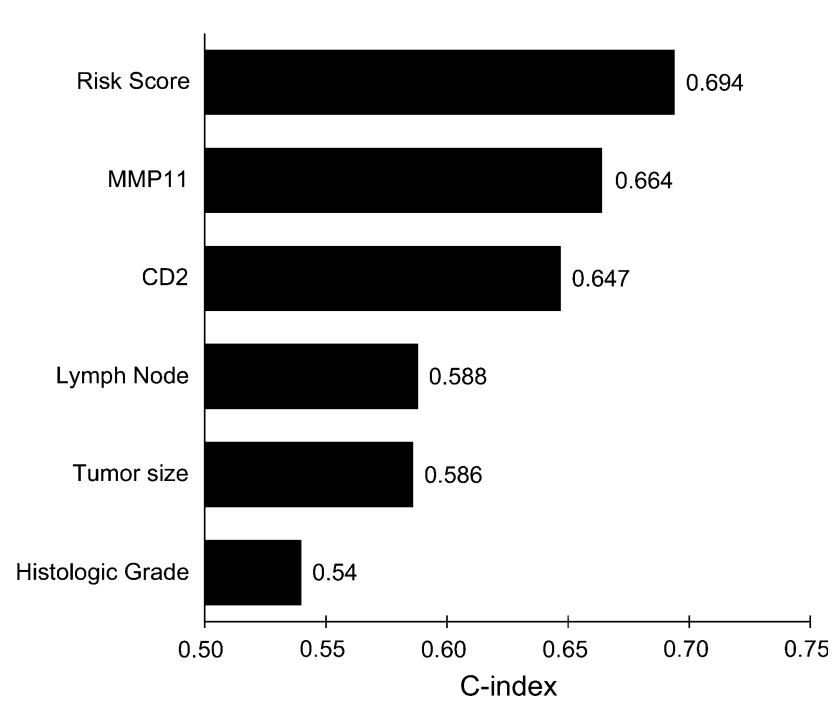

Fig. 2 Prognostic performance of our risk score in predicting distant metastasis in HR-/HER2 + breast cancer compared with that of traditional clinicopathological parameters based on C-index. Values on the $x$-axis are unbiased estimates of the C-index of the linear combination of one or more variables by Cox regression

and provides more accurate prognostic information than traditional clinicopathological factors in this subtype of breast cancer.

\section{Prognostic significance of $M M P 11$ and $C D 2$ expression in HR-/HER2 + breast cancer in public dataset}

We also examined the relationship between MMP11 and $C D 2$ gene expression and prognosis of patients with $\mathrm{HR}-/$ HER2 + breast cancer using public dataset to confirm their clinical significance in other cohorts. Gene expression and clinical data from METABRIC (Molecular Taxonomy of Breast Cancer International Consortium) cohort [28] were obtained from cBioPortal (http://www.cbioportal.org/) [29]. Consistent with the results in our cohort, significantly shorter OS in patients with high MMP11 expression than those with low MMP11 expression was observed $(P=0.030)$, whereas patients with high $C D 2$ expression had a significantly longer OS than those with low $C D 2$ expression ( $P=0.027$ ) (Fig. 3).

\section{Discussion}

Based on the 384 genes identified from our previous study, we selected 16 candidate prognostic genes, and assessed the association between their expression and patient outcome in different molecular subtypes of breast cancer.

Univariate analysis identified significant factors correlated with distant metastasis in different molecular subtypes of breast cancer. Among the traditional clinicopathological factors, LN status showed a significant relationship with DMFS and DFS in all molecular subtypes except HR-/HER2 + breast cancer. Of note, larger tumor size was significantly associated with higher risk of distant metastasis in HER2 - breast cancer, but not HER2 + breast cancer. Moreover, we identified subtype-specific prognostic genes whose expression was significantly associated with the risk of distant metastasis. Higher expression of most of the p-genes correlated significantly with a higher risk of distant metastasis in HR+/HER2 - cancer, whereas no significance was observed in TNBC. These results are consistent with the previous finding that proliferation is the most important component of the prognostic signature in ER + breast cancer [12]. Our study provides novel proliferation-related prognostic gene sets for HR+ breast cancer that may be used to develop a multigene assay for predicting the risk of distant recurrence and thereby identify patients who will benefit from specific treatment in this subtype.

In addition, elevated expression of i-genes (BTN $3 A 2$, $C D 2$, and $T R B C 1$ ) was significantly correlated with favorable clinical outcome in HR-/HER2+ breast cancer, but not in other subtypes. The prognostic value of immune 

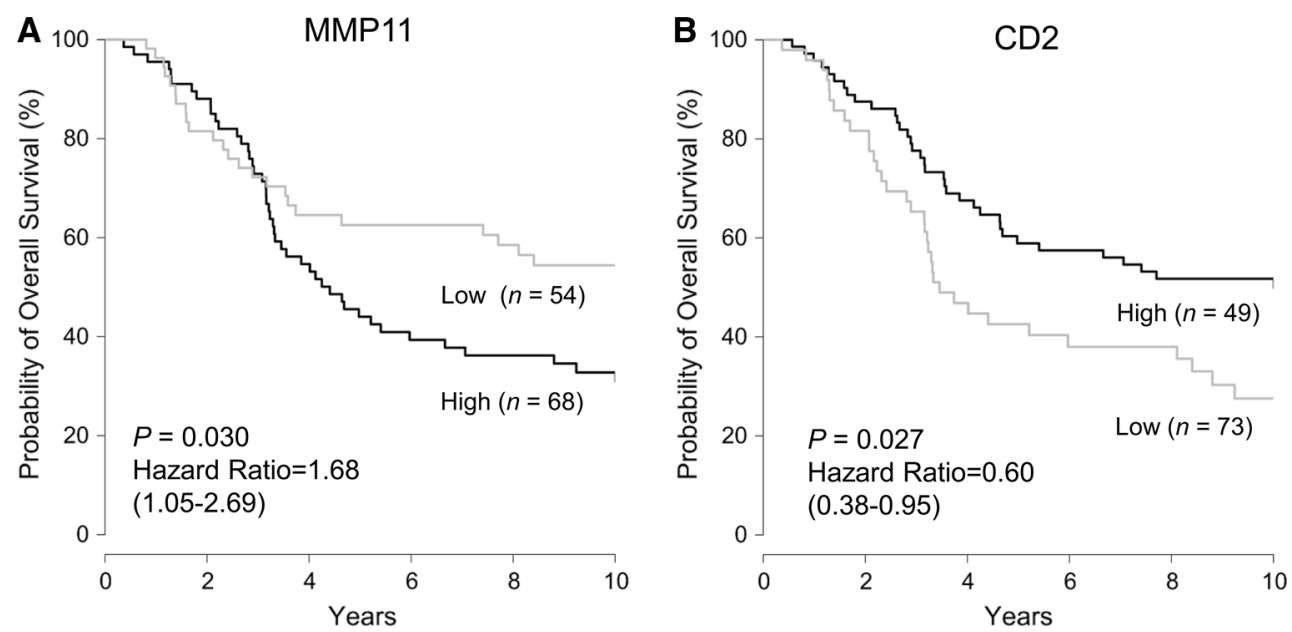

Fig. 3 Prognostic significance of $M M P 11$ and $C D 2$ gene expression in public dataset. Kaplan-Meier plot of overall survival in two subgroups classified based on the expression of $\mathbf{a} M M P 11$ or $\mathbf{b} C D 2$ in patients with HR-/HER2+ breast cancer from Molecular Taxonomy of Breast Cancer International Consortium (METABRIC) cohort

gene signatures as predictors of distant metastasis in HRbreast cancer has been reported $[13,14,16]$. In particular, both $B T N 3 A 2$ and $C D 2$ are involved in the T-cell immune response. However, it is difficult to exclude the possibility that the increased expression of these genes is due to infiltrating immune cells. The prognostic significance of infiltrating immune cells as a key component of the tumor microenvironment has been recognized for breast cancer, and a positive correlation between lymphocyte infiltration or expression of lymphocyte-associated genes and HER2 amplification/overexpression in breast cancer has been reported [30, 31]. Moreover, higher expression of lymphocyte-associated genes is associated with a favorable prognosis in HER2+ breast cancer [30-32]. Our findings further expand the prognostic significance of $\mathrm{i}$-genes in HR-/HER2 + breast cancer. It is notable that among i-genes, T-cell-related genes are associated with favorable prognosis of HR-/HER2+ breast cancer in our study. This is supported by a recent study reporting that T-cells, but not B-cells, have significant prognostic value in HER2+ breast cancer [32].

Interestingly, a recent study revealed that $\mathrm{CD} 2$ is critical for antibody-dependent responses by adaptive natural killer (NK) cells, suggesting an important role for CD2 in stimulating the NK cell response to therapeutic antibodies [33]. This recent finding raises the possibility that the correlation between high $C D 2$ expression and favorable prognosis of patients with HR-/HER2+ breast cancer in our study is related to the augmentation of NK cytotoxic activity against cancer cells by CD2. However, this relationship was not assessed in this study, and further studies designed to unravel the association between $C D 2$ expression and anti-HER2 antibody response or the value of $C D 2$ in predicting anti-HER2 antibody response in HER2 + breast cancer will be required.
Importantly, we found that the gene expression of $M M P 11$ and $C D 2$ are independent prognostic factors for DMFS in HR-/HER2+ breast cancer, whereas clinical variables were not significant prognostic indicators. With regard to prognostic models for HR-/HER2+ breast cancer, several attempts have been made to identify prognostic multigene signatures for this subtype using gene expression microarray data, but a few validated prognostic genes have been established. In this context, it is important that the expression of MMP11 and $C D 2$ are validated as independent prognostic factors and this is in line with previous studies showing that the main gene signatures associated with prognosis in HER2+ breast cancer include genes related to tumor invasion and immune response [12, 34]. The roles of MMP11 in tumor progression have been reported in breast cancer. Its overexpression promotes anoikis resistance [35] and enhances tumorigenesis in HER2- breast cancer cell lines via IGF-1 signaling [36]. Recent studies also showed that MMP11 is a downstream target of oncogene or tumor suppressor microRNA, thereby contributes to tumor cell migration, invasion, or angiogenesis in breast cancer cells. Oncogenic transcription factor Gli1 promotes migration and invasion of ER - breast cancer cells through the up-regulation of MMP11 [37] and reduced MMP11 expression mediates the anti-angiogenic and invasion effect of microRNA miR-98 in ER- breast cancer cells [38]. However, the clinical and functional significance of MMP11 in HR-/HER2+ breast cancer remains unclear. Here, our findings demonstrate for the first time the prognostic significance of MMP11 and $C D 2$ expression in HR-/HER2+ breast cancer and suggest that they are promising biomarkers or drug targets for this subtype of breast cancer. Further studies for validation will be required. 
Generally, patients with ER- breast cancer have a worse prognosis than those with ER+ breast cancer [39-41]. In contrast, there were no statistically significant differences in patient survivals between molecular subtypes during the entire follow-up period in our study. This discrepancy may be in part due to the chemotherapy effects on the subtypes. Most patients (86.3\%) including TNBC patients $(92.7 \%)$ of our study received adjuvant chemotherapy and our previous study [19] demonstrated that TNBC patients with chemotherapy had significantly longer DFS and OS than those without chemotherapy, whereas TNBC without chemotherapy showed a relatively worse prognosis. However, a significant population of ER - breast cancer cases not receiving adjuvant chemotherapy has a good prognosis [34]. More accurately identifying these patients is important because this population may benefit from less aggressive therapy. Our data revealed a significant difference in DMFS between highrisk and low-risk groups as defined by our prognostic model, illustrating that our model can discriminate patients at low risk and high risk of distant metastasis in $\mathrm{HR}-$ / HER2+ breast cancer. Therefore, our prognostic model may help to guide treatment for patients with $\mathrm{HR}-$ / HER2 + breast cancer by identifying those with a good prognosis within this subtype.

\section{Conclusions}

In summary, we identified molecular subtype-specific novel prognostic genes in breast cancer and developed a novel prognostic model to predict the risk of distant metastasis for HR-/HER2+ breast cancer based on the gene expression of MMP11 and CD2. Our prognostic model was superior to traditional clinicopathological factors in prognostic performance and may be used in identifying patients with good prognosis from this aggressive subtype of breast cancer. Consequently, the novel prognostic genes validated in this study may be used to develop assays to accurately predict the prognosis of these patients and thereby provide useful information for determining treatment options in patients with HR-/HER2+ breast cancer.

\footnotetext{
Acknowledgments We thank Garam Park for her support with clinical data processing and we are grateful to Si Eun Kim and Sumin Kim for their technical assistance. This research was supported by the Basic Science Research Program through the National Research foundation of Korea (NRF) funded by the Ministry of Education (Grant No.: NRF-2015R1D1A1A01056695) and a grant of the Korea Health Technology R\&D Project through the Korea Health Industry Development Institute (KHIDI), funded by the Ministry of Health \& Welfare, Republic of Korea (Grant No.: A111129).
}

Author contributions YKS and YLC conceived the study and participated in its design. MJK, JH, and $\mathrm{HK}$ drafted the manuscript. MJK, JH, HK, and YLC participated in the analysis and interpretation of the data. YLC and JSC (Jong-Sun Choi) were involved in the acquisition of data. $\mathrm{JH}$ and $\mathrm{HK}$ performed the statistical analyses. JYC, SKL, JEL, JSC (Joon-Seok Choi), YDK, SJN, and YLC provided administrative, technical or material support. BHN supervised the statistical analyses. SP participated in critical revision of the manuscript for important intellectual content. YKS supervised the study. All authors read and approved the final manuscript.

\section{Compliance with ethical standards}

Conflict of interest $\mathrm{JH}$ is a salaried employee of Gencurix. YDK is a salaried employee of ABION. YKS and JH hold a patent application related to the content of this article. The other authors declare that they have no competing interests.

Open Access This article is distributed under the terms of the Creative Commons Attribution 4.0 International License (http://creative commons.org/licenses/by/4.0/), which permits unrestricted use, distribution, and reproduction in any medium, provided you give appropriate credit to the original author(s) and the source, provide a link to the Creative Commons license, and indicate if changes were made.

\section{References}

1. Coates AS, Winer EP, Goldhirsch A, Gelber RD, Gnant M, Piccart-Gebhart M, Thurlimann B, Senn HJ (2015) Tailoring therapies-improving the management of early breast cancer: St Gallen International Expert Consensus on the Primary Therapy of Early Breast Cancer 2015. Ann Oncol 26(8):1533-1546. doi:10. 1093/annonc/mdv221

2. Sorlie T, Perou CM, Tibshirani R, Aas T, Geisler S, Johnsen H, Hastie T, Eisen MB, van de Rijn M, Jeffrey SS, Thorsen T, Quist H, Matese JC, Brown PO, Botstein D, Lonning PE, Borresen-Dale AL (2001) Gene expression patterns of breast carcinomas distinguish tumor subclasses with clinical implications. Proc Natl Acad Sci USA 98(19):10869-10874. doi:10.1073/pnas.191367098

3. Sotiriou C, Neo SY, McShane LM, Korn EL, Long PM, Jazaeri A, Martiat P, Fox SB, Harris AL, Liu ET (2003) Breast cancer classification and prognosis based on gene expression profiles from a population-based study. Proc Natl Acad Sci USA 100(18):10393-10398. doi:10.1073/pnas.1732912100

4. Parker JS, Mullins M, Cheang MC, Leung S, Voduc D, Vickery T, Davies S, Fauron C, He X, Hu Z, Quackenbush JF, Stijleman IJ, Palazzo J, Marron JS, Nobel AB, Mardis E, Nielsen TO, Ellis MJ, Perou CM, Bernard PS (2009) Supervised risk predictor of breast cancer based on intrinsic subtypes. J Clin Oncol 27(8):1160-1167. doi:10.1200/JCO.2008.18.1370

5. Paik S, Shak S, Tang G, Kim C, Baker J, Cronin M, Baehner FL, Walker MG, Watson D, Park T, Hiller W, Fisher ER, Wickerham DL, Bryant J, Wolmark N (2004) A multigene assay to predict recurrence of tamoxifen-treated, node-negative breast cancer. N Engl J Med 351(27):2817-2826. doi:10.1056/NEJMoa041588

6. Paik S, Tang G, Shak S, Kim C, Baker J, Kim W, Cronin M, Baehner FL, Watson D, Bryant J, Costantino JP, Geyer CE Jr, Wickerham DL, Wolmark N (2006) Gene expression and benefit of chemotherapy in women with node-negative, estrogen receptor-positive breast cancer. J Clin Oncol 24(23):3726-3734. doi:10.1200/JCO.2005.04.7985 
7. van de Vijver MJ, He YD, van't Veer LJ, Dai H, Hart AA, Voskuil DW, Schreiber GJ, Peterse JL, Roberts C, Marton MJ, Parrish M, Atsma D, Witteveen A, Glas A, Delahaye L, van der Velde T, Bartelink H, Rodenhuis S, Rutgers ET, Friend SH, Bernards R (2002) A gene-expression signature as a predictor of survival in breast cancer. N Engl J Med 347(25):1999-2009. doi:10.1056/NEJMoa021967

8. van't Veer LJ, Dai H, van de Vijver MJ, He YD, Hart AA, Mao M, Peterse HL, van der Kooy K, Marton MJ, Witteveen AT, Schreiber GJ, Kerkhoven RM, Roberts C, Linsley PS, Bernards R, Friend SH (2002) Gene expression profiling predicts clinical outcome of breast cancer. Nature 415(6871):530-536. doi:10. 1038/415530a

9. Nielsen TO, Parker JS, Leung S, Voduc D, Ebbert M, Vickery T, Davies SR, Snider J, Stijleman IJ, Reed J, Cheang MC, Mardis ER, Perou CM, Bernard PS, Ellis MJ (2010) A comparison of PAM50 intrinsic subtyping with immunohistochemistry and clinical prognostic factors in tamoxifen-treated estrogen receptorpositive breast cancer. Clin Cancer Res 16(21):5222-5232. doi:10.1158/1078-0432.CCR-10-1282

10. Dowsett M, Sestak I, Lopez-Knowles E, Sidhu K, Dunbier AK, Cowens JW, Ferree S, Storhoff J, Schaper C, Cuzick J (2013) Comparison of PAM50 risk of recurrence score with oncotype DX and IHC4 for predicting risk of distant recurrence after endocrine therapy. J Clin Oncol 31(22):2783-2790. doi:10.1200/ JCO.2012.46.1558

11. Filipits M, Rudas M, Jakesz R, Dubsky P, Fitzal F, Singer CF, Dietze O, Greil R, Jelen A, Sevelda P, Freibauer C, Muller V, Janicke F, Schmidt M, Kolbl H, Rody A, Kaufmann M, Schroth W, Brauch H, Schwab M, Fritz P, Weber KE, Feder IS, Hennig G, Kronenwett R, Gehrmann M, Gnant M (2011) A new molecular predictor of distant recurrence in ER-positive, HER2negative breast cancer adds independent information to conventional clinical risk factors. Clin Cancer Res 17(18):6012-6020. doi:10.1158/1078-0432

12. Desmedt C, Haibe-Kains B, Wirapati P, Buyse M, Larsimont D, Bontempi G, Delorenzi M, Piccart M, Sotiriou C (2008) Biological processes associated with breast cancer clinical outcome depend on the molecular subtypes. Clin Cancer Res 14(16):5158-5165. doi:10.1158/1078-0432

13. Yau C, Esserman L, Moore DH, Waldman F, Sninsky J, Benz CC (2010) A multigene predictor of metastatic outcome in early stage hormone receptor-negative and triple-negative breast cancer. Breast Cancer Res 12(5):R85. doi:10.1186/bcr2753

14. Teschendorff AE, Miremadi A, Pinder SE, Ellis IO, Caldas C (2007) An immune response gene expression module identifies a good prognosis subtype in estrogen receptor negative breast cancer. Genome Biol 8(8):R157. doi:10.1186/gb-2007-8-8-r157

15. Teschendorff AE, Caldas C (2008) A robust classifier of high predictive value to identify good prognosis patients in ER-negative breast cancer. Breast Cancer Res 10(4):R73. doi:10.1186/ bcr2138

16. Yau C, Sninsky J, Kwok S, Wang A, Degnim A, Ingle JN, Gillett C, Tutt A, Waldman F, Moore D, Esserman L, Benz CC (2013) An optimized five-gene multi-platform predictor of hormone receptor negative and triple negative breast cancer metastatic risk. Breast Cancer Res 15(5):R103. doi:10.1186/bcr3567

17. Oh E, Choi YL, Park T, Lee S, Nam SJ, Shin YK (2012) A prognostic model for lymph node-negative breast cancer patients based on the integration of proliferation and immunity. Breast Cancer Res Treat 132(2):499-509. doi:10.1007/s10549-0111626-8

18. Altman DG, McShane LM, Sauerbrei W, Taube SE (2012) Reporting recommendations for tumor marker prognostic studies (REMARK): explanation and elaboration. PLoS Med 9(5):e1001216. doi:10.1371/journal.pmed.1001216
19. Choi YL, Oh E, Park S, Kim Y, Park YH, Song K, Cho EY, Hong YC, Choi JS, Lee JE, Kim JH, Nam SJ, Im YH, Yang JH, Shin YK (2010) Triple-negative, basal-like, and quintuple-negative breast cancers: better prediction model for survival. BMC Cancer 10:507. doi:10.1186/1471-2407-10-507

20. Tournoud M, Larue A, Cazalis MA, Venet F, Pachot A, Monneret G, Lepape A, Veyrieras JB (2015) A strategy to build and validate a prognostic biomarker model based on RT-qPCR gene expression and clinical covariates. BMC Bioinform 16:106. doi:10.1186/s12859-015-0537-9

21. Haybittle JL, Blamey RW, Elston CW, Johnson J, Doyle PJ, Campbell FC, Nicholson RI, Griffiths K (1982) A prognostic index in primary breast cancer. Br J Cancer 45(3):361-366

22. Chen LL, Nolan ME, Silverstein MJ, Mihm MC Jr, Sober AJ, Tanabe KK, Smith BL, Younger J, Michaelson JS (2009) The impact of primary tumor size, lymph node status, and other prognostic factors on the risk of cancer death. Cancer 115(21):5071-5083. doi:10.1002/cncr.24565

23. Wishart GC, Azzato EM, Greenberg DC, Rashbass J, Kearins O, Lawrence G, Caldas C, Pharoah PD (2010) PREDICT: a new UK prognostic model that predicts survival following surgery for invasive breast cancer. Breast Cancer Res 12(1):R1. doi:10.1186/ bcr2464

24. Wishart GC, Bajdik CD, Dicks E, Provenzano E, Schmidt MK, Sherman M, Greenberg DC, Green AR, Gelmon KA, Kosma VM, Olson JE, Beckmann MW, Winqvist R, Cross SS, Severi G, Huntsman D, Pylkas K, Ellis I, Nielsen TO, Giles G, Blomqvist C, Fasching PA, Couch FJ, Rakha E, Foulkes WD, Blows FM, Begin LR, van't Veer LJ, Southey M, Nevanlinna H, Mannermaa A, Cox A, Cheang M, Baglietto L, Caldas C, Garcia-Closas M, Pharoah PD (2012) PREDICT Plus: development and validation of a prognostic model for early breast cancer that includes HER2. Br J Cancer 107(5):800-807. doi:10.1038/bjc.2012.338

25. Harrell FE, Lee KL, Mark DB (1996) Tutorial in biostatistics multivariable prognostic models: issues in developing models, evaluating assumptions and adequacy, and measuring and reducing errors. Stat Med 15:361-387

26. Kwon MJ, Park S, Choi JY, Oh E, Kim YJ, Park YH, Cho EY, Nam SJ, Im YH, Shin YK, Choi YL (2012) Clinical significance of CD151 overexpression in subtypes of invasive breast cancer. Br J Cancer 106(5):923-930. doi:10.1038/bjc.2012.11

27. McCall MN, McMurray HR, Land H, Almudevar A (2014) On non-detects in qPCR data. Bioinformatics 30(16):2310-2316. doi:10.1093/bioinformatics/btu239

28. Curtis C, Shah SP, Chin SF, Turashvili G, Rueda OM, Dunning MJ, Speed D, Lynch AG, Samarajiwa S, Yuan Y, Graf S, Ha G, Haffari G, Bashashati A, Russell R, McKinney S, Langerod A, Green A, Provenzano E, Wishart G, Pinder S, Watson P, Markowetz F, Murphy L, Ellis I, Purushotham A, Borresen-Dale AL, Brenton JD, Tavare S, Caldas C, Aparicio S (2012) The genomic and transcriptomic architecture of 2,000 breast tumours reveals novel subgroups. Nature 486(7403):346-352. doi:10.1038/ nature 10983

29. Cerami E, Gao J, Dogrusoz U, Gross BE, Sumer SO, Aksoy BA, Jacobsen A, Byrne CJ, Heuer ML, Larsson E, Antipin Y, Reva B, Goldberg AP, Sander C, Schultz N (2012) The cBio cancer genomics portal: an open platform for exploring multidimensional cancer genomics data. Cancer Discov 2(5):401-404. doi:10.1158/2159-8290

30. Alexe G, Dalgin GS, Scanfeld D, Tamayo P, Mesirov JP, DeLisi C, Harris L, Barnard N, Martel M, Levine AJ, Ganesan S, Bhanot G (2007) High expression of lymphocyte-associated genes in nodenegative HER2 + breast cancers correlates with lower recurrence rates. Can Res 67(22):10669-10676. doi:10.1158/0008-5472

31. Tsang JY, Hui SW, Ni YB, Chan SK, Yamaguchi R, Kwong A, Law BK, Tse GM (2014) Lymphocytic infiltrate is associated 
with favorable biomarkers profile in HER2-overexpressing breast cancers and adverse biomarker profile in ER-positive breast cancers. Breast Cancer Res Treat 143(1):1-9. doi:10.1007/ s10549-013-2781-x

32. Rody A, Holtrich U, Pusztai L, Liedtke C, Gaetje R, Ruckhaeberle E, Solbach C, Hanker L, Ahr A, Metzler D, Engels K, Karn T, Kaufmann M (2009) T-cell metagene predicts a favorable prognosis in estrogen receptor-negative and HER2-positive breast cancers. Breast Cancer Res 11(2):R15. doi:10.1186/bcr2234

33. Liu LL, Landskron J, Ask EH, Enqvist M, Sohlberg E, Traherne JA, Hammer Q, Goodridge JP, Larsson S, Jayaraman J, Oei VY, Schaffer M, Tasken K, Ljunggren HG, Romagnani C, Trowsdale J, Malmberg KJ, Beziat V (2016) Critical role of CD2 co-stimulation in adaptive natural killer cell responses revealed in NKG2C-deficient humans. Cell Rep 15(5):1088-1099. doi:10. 1016/j.celrep.2016.04.005

34. Staaf J, Ringner M, Vallon-Christersson J, Jonsson G, Bendahl PO, Holm K, Arason A, Gunnarsson H, Hegardt C, Agnarsson BA, Luts L, Grabau D, Ferno M, Malmstrom PO, Johannsson OT, Loman N, Barkardottir RB, Borg A (2010) Identification of subtypes in human epidermal growth factor receptor 2-positive breast cancer reveals a gene signature prognostic of outcome. J Clin Oncol 28(11):1813-1820. doi:10.1200/JCO.2009.22.8775

35. Takeuchi T, Adachi Y, Nagayama T, Furihata M (2011) Matrix metalloproteinase-11 overexpressed in lobular carcinoma cells of the breast promotes anoikis resistance. Virchows Arch 459(3):291-297. doi:10.1007/s00428-011-1125-7

36. Kasper G, Reule M, Tschirschmann M, Dankert N, Stout-Weider K, Lauster R, Schrock E, Mennerich D, Duda GN, Lehmann KE
(2007) Stromelysin-3 over-expression enhances tumourigenesis in MCF-7 and MDA-MB-231 breast cancer cell lines: involvement of the IGF-1 signalling pathway. BMC Cancer 7:12. doi:10. 1186/1471-2407-7-12

37. Kwon YJ, Hurst DR, Steg AD, Yuan K, Vaidya KS, Welch DR, Frost AR (2011) Gli1 enhances migration and invasion via upregulation of MMP-11 and promotes metastasis in ERalpha negative breast cancer cell lines. Clin Exp Metastasis 28(5):437-449. doi:10.1007/s10585-011-9382-Z

38. Siragam V, Rutnam ZJ, Yang W, Fang L, Luo L, Yang X, Li M, Deng Z, Qian J, Peng C, Yang BB (2012) MicroRNA miR-98 inhibits tumor angiogenesis and invasion by targeting activin receptor-like kinase- 4 and matrix metalloproteinase-11. Oncotarget 3(11):1370-1385.

39. Sorlie T, Tibshirani R, Parker J, Hastie T, Marron JS, Nobel A, Deng S, Johnsen H, Pesich R, Geisler S, Demeter J, Perou CM, Lonning PE, Brown PO, Borresen-Dale AL, Botstein D (2003) Repeated observation of breast tumor subtypes in independent gene expression data sets. Proc Natl Acad Sci USA 100(14):8418-8423. doi:10.1073/pnas.0932692100

40. Carey LA, Perou CM, Livasy CA, Dressler LG, Cowan D, Conway K, Karaca G, Troester MA, Tse CK, Edmiston S, Deming SL, Geradts J, Cheang MC, Nielsen TO, Moorman PG, Earp HS, Millikan RC (2006) Race, breast cancer subtypes, and survival in the Carolina Breast Cancer Study. JAMA 295(21):2492-2502. doi:10.1001/jama.295.21.2492

41. Perou CM, Borresen-Dale AL (2011) Systems biology and genomics of breast cancer. Cold Spring Harb Perspect Biol. doi:10.1101/cshperspect.a003293 